\title{
Interactive comment on "Mapping and inventorying active rock glaciers in the Northern Tien Shan (China) using satellite SAR interferometry" by Xiaowen Wang et al.
}

\section{T. Strozzi (Referee)}

strozzi@gamma-rs.ch

Received and published: 13 December 2016

The manuscript by Wang et al. nicely describes the application of SAR interferometry and Google Earth optical images to the mapping of active rock glaciers in the Northern Tien Shan. The structure of the paper is solid, the objectives of the work are clearly stated, the employed technology is well explained, the results are nicely described and illustrated, and the conclusions are well formulated. Although not completely novel, the approach of mapping and inventorying active rock glaciers from SAR interferometry and optical images is here throughout applied for the first time in the high mountains of western China, revealing new insights into rock glaciers as proxies of permafrost. The same approach presented by Wang et al. can be used for the systematic investiga- 
tions of rock glaciers, and thus permafrost, over other remote mountainous locations. Considering the excellent work done by the authors in the redaction of the manuscript, I only have a few specific comments.

1. The short description about error sources in SAR interferograms at line 138 could be expanded a little bit to avoid the impression that their effects are not well considered or underestimated. In particular, the use of a coarse resolution DEM as SRTM results in uncompensated phase signals that scale up with the baseline of the interferograms. The authors state that maximum baselines considered in their studies are $600 \mathrm{~m}$, but I would expect here a quantitative estimate of the phase disturbances that may occur in high mountains as a consequence of typical SRTM height errors or artefacts. In addition, a statement about the different distortions that occur with respect to the slope and orientation of the rock glaciers and the satellite line-of-sight direction should be included. Then, on the same paragraph, a short comment on the typical atmospheric disturbances at L-band with respect to the size of the active rock glaciers would be beneficial to strengthen the potential of the technology. Finally, Barboux et al. (2015) found out that phase unwrapping is the major limiting factor to the use of SAR interferometry for monitoring active rock glaciers in the Swiss Alps. In their paper, Wang et al. are not discussing at all possible phase unwrapping errors. I did some rapid calculations with the active rock glaciers velocities reported by the authors in the Northern Tien Shan. If maximum down-slope velocities of active rock glaciers in this region are about $114 \mathrm{~cm}$ $\mathrm{yr}-1$, then the maximum line-of-sight velocities should be about 2/3 of the down-slope direction, i.e. about $76 \mathrm{~cm}$ yr-1. Over a time period of 46 days this would correspond to about $10 \mathrm{~cm}$ or less than one fringe a L-band. Indeed, in the Northern Tien Shan phase unwrapping is not a relevant issue, but this is not the case in many other mountain regions. Therefore, a short comment on phase unwrapping with respect to the velocities of the active rock glaciers should be included in the manuscript.

2. At line 63, the paper by Strozzi et al. (2010) is about landslides, not rock glaciers. Use instead Strozzi et al. (2004): Strozzi T., A. Kääb and R. Frauenfelder, Detecting

Printer-friendly version

Discussion paper 
and quantifying mountain permafrost creep from in situ inventory, space-borne radar interferometry and airborne digital photogrammetry, Int. J. Remote Sensing, Vol. 25, No. 15, pp. 2919-2931, doi: 10.1080/0143116042000192330 2004.

3. Figure $9 \mathrm{a}$ is nearly impossible to interpret, there is too much information and there are too many colours and symbols. An alternative representation of this image should be proposed by the authors.

Interactive comment on The Cryosphere Discuss., doi:10.5194/tc-2016-254, 2016. 